\title{
Post-Affirmative Action Supreme Court Decision: New Challenges for Academic Institutions
}

\author{
Lisa A. Tedesco, Ph.D. \\ Abstract: This article describes several aspects of the University of Michigan Supreme Court cases regarding diversity in higher \\ education. It provides a number of resources that are useful in shaping the rationale and institutional practices and policies for \\ admissions and the recruitment and retention of diverse classes of students for the health professions. \\ Dr. Tedesco is a Professor, University of Michigan School of Dentistry and is, in 2005-06, Visiting Professor, School of Dental \\ and Oral Surgery and Visiting Fellow, Center for Community Health Partnerships, Columbia University. From 1998 to 2005 she \\ served as Vice President and Secretary of the University of Michigan. Direct correspondence and requests for reprints to her at \\ the University of Michigan School of Dentistry, 1011 North University Avenue, Ann Arbor, MI 48109; 734-763-2105 phone; \\ 734-763-5503 fax; 1tedesco@umich.edu.
}

Key words: health workforce diversity, recruitment and retention, admissions, educational benefits of diversity, affirmative action

Submitted for publication $7 / 12 / 05$; accepted $8 / 22 / 05$

$\mathrm{T}$ his article describes several aspects of the University of Michigan Supreme Court cases regarding diversity in higher education. In addition, it provides a number of resources that are useful in shaping the rationale and institutional practices and policies for admissions and the recruitment and retention of diverse classes of students for the health professions. Parts of the article reflect a narrative tone that portrays the meaning and value of this work to me. An earlier version of this article was presented at the American Dental Education Association's Sixth National Minority Recruitment and Retention Conference in October 2004.

I was privileged to work with both Lee Bollinger, as president, and Nancy Cantor, as provost, during their tenure at the University of Michigan. It was their articulation of our cases, the potential of a Supreme Court hearing, and their values-based leadership that drew me away from my post as associate dean for academic affairs in the School of Dentistry in 1998. From almost day one of their time in leadership at Michigan, an admissions challenge ending up at the Supreme Court was expected. To meet this challenge, they assembled a diverse team who shared an understanding of what diversity means to educational settings and educational outcomes.

One thing I learned during my work on this team is the importance of visible, articulate leadership on the benefits of diversity and its importance to a complete education. Bollinger and Cantor had utter clarity and extraordinary courage to stay the course. In the face of suggestions, recommendations, and even urgings from prominent individuals close to and within the university that the fight would not be winnable, they were clear and unwavering about the benefits, value, and importance of preserving the university's right to assemble diverse classes of students. They had this clarity at day one and communicated their beliefs to me in a way that convinced me to take on an administrative assignment during their tenure.

As president and provost, they knew and understood that the University of Michigan has been committed, from its founding, to providing an education to the widest range of students. Throughout our history the university has been marked by student diversity in geography, race, ethnicity, and social and economic background. Even in 1997, at the very beginning of the challenge to our affirmative action policies and practices, Bollinger gave voice to our institutional history, saying that "for almost 200 years, public universities have unlocked the doors to social and economic opportunity to students from many different backgrounds and we believe it is absolutely essential that they continue to do so. Our mission and core expertise is to create the best educational environment we can. We do this in part through a diverse faculty and student body." In this statement is a core value that is coupled with con- 
stancy, supported by the institution at all levels. The university's leadership held then, and does still today, a deep understanding of what diversity means to the academy's work, excellence, and society.

Like Bollinger and Cantor, current University of Michigan President Mary Sue Coleman has provided excellent leadership and is following through at all levels and on all fronts. "These rulings in support of affirmative action will go down in history as among the great landmark decisions of the Supreme Court," she has said. "And I am proud of the voice the University of Michigan provided in this important debate. We fought for the very principle that defines our country's greatness. Year after year, our student body proves it and now the court has affirmed it: Our diversity is our strength."

Building on the principal that diversity is a strength necessary for institutional excellence, I will address three areas here: the value of diversity in higher education; how race can be legally considered in the admissions process; and how to move admissions practices forward to increase diversity. I will also share additional observations that, in my view, see admissions and pipeline challenges systemically.

\section{The Value of Diversity in Higher Education: Educational and Civic Outcomes from Diversity}

Not until very recently, since the onset of the challenge to affirmative action in higher education, did a number of primary and secondary studies emerge that provide comprehensive analyses on the benefits of diversity in undergraduate education. These studies along with specific research, expert testimony, and amicus briefs that were prepared for the Michigan cases remain available on the Michigan website. ${ }^{3}$ The educational benefits of diversity span a range of positive outcomes that not only contribute to a graduate's success in life, but also to society's well-being, by creating social capital. Social capital (the group or community benefits that result from strong and cohesive bonds among individuals) is increasingly being recognized as a force important to addressing health care needs, in general, and health disparities, in particular. ${ }^{4,5}$
The work of many authorities provides key evidence on the educational benefits of diversity. Bowen and Bok, ${ }^{6}$ Gurin,,${ }^{7-12}$ Light, ${ }^{13}$ the Astin group, ${ }^{14-16}$ and Orfield et al. ${ }^{17-19}$ produced findings (which I have summarized elsewhere ${ }^{20}$ ) crucially important to establishing a strong line of evidence on the educational benefits of diversity. All these experts are closely tied to both undergraduate education and education in the professions.

In the book The Shape of the River, ${ }^{6}$ the authors report on a large database constructed between 1994 and 1997 by the Mellon Foundation in cooperation with twenty-eight selective colleges and universities. The outcomes discussed represent approximately 30,000 graduates in 1976 and 1989. The data show that abilities and performance of minority students admitted to selective schools, where race was important to the creation of a diverse student body, have been outstanding. Some key findings are:

- Minority students have graduated in large numbers. In the 1989 cohort overall the graduation rate for black matriculants was 75 percent, and the national benchmark for this period was 40 percent. The graduation rate for whites during this period was 86 percent, with the national rate at 59 percent.

- Matriculants at the selective schools completed a range of advanced degrees at a higher percentage than other graduates nationally. The data show, in a similar pattern for both cohorts, that especially large fractions from the selective schools received professional degrees (those in law, medicine, business): 40 percent of all black graduates and 37 percent of white graduates. The national figures respectively are 8 and 12 percent.

- Bowen and Bok also tell us that black graduates from the selective schools were slightly more likely than white graduates to earn degrees in law and medicine. And, when compared with the general college population, black graduates were seven times more likely to gain degrees in law and five times more likely in medicine.

- Civic engagement and community service are particularly high among minorities from the selective schools and in greater numbers than their white counterparts. Black men, in particular, were especially likely to be involved with community, social service, youth, and educational activities. For each type of activity, black involvement was several percentage points higher than white involvement. 
Bowen and Bok go on to emphasize, in every type of community or volunteer activity in their study, that the ratio of black male leaders to white male leaders is even higher than that of black to white male participants. When these data were examined for differences within advanced degree groups, black leadership exceeded white leadership across the board, with the largest differences in law, medicine, business, and at the doctoral degree level. For sure, these outcomes are rich social capital findings.

One final analysis from The Shape of the River must be emphasized. Bowen and Bok examined what society would have lost if race-conscious admissions had not been used at the schools in their study. They used a methodology of "retrospectively rejecting" students if the schools employed race-neutral approaches. Using the 1976 cohort of matriculants, they estimated that 700 students would have been rejected. Over 225 members of the groups of retrospectively rejected black matriculants went on to attain professional degrees or doctorates. About seventy are physicians; sixty are lawyers; approximately 125 are business executives; and well over 300 are reported to be leaders of civic activities. In short, denying our institutions the benefit of this diversity would have been at great expense to individual development and social capital.

Another body of work from Gurin et al. ${ }^{7-12}$ provides a focus on academic-intellectual benefits, as well as interpersonal group relations benefits. The expert testimony provided by Gurin was a central and crucial piece of the University of Michigan's defense of race-conscious admissions.

This body of research demonstrates that a critical task during adolescence is the development of understanding that there are multiple views of the world and understanding what it means to have a life experience different from your own. Equally essential is learning again and again to test your assumptions about how people view the world and that sometimes you expect someone to think differently from you, when in fact they do not. This development reaches its potential in the classroom and other social environments where diversity is present. Thinking through your own perceptions, becoming reflective and capable of characterizing another view when it is not your own, and engaging in effective problem solving and critical thinking are the important, extremely valuable benefits from an education where diversity exists in the classroom. Research shows that students with diversity experiences during college become more active and thoughtful learn- ers and are better prepared to participate in a heterogeneous society.

Three studies that looked at the concept of "learning outcomes" in the classroom also showed the importance of diversity of learning and preparation for participants in society. These studies were a multi-institutional analysis from data supplied by the Cooperative Institutional Research Program (CIRP) of more than 9,000 students entering 184 colleges and universities in 1985; the Michigan Student Study (MSS), an extensive study of the University of Michigan entering undergraduate class of 1994 (participants were 187 African American students and 1,134 white students); and another study of University of Michigan students from a class in the Intergroup Relations Community and Conflict Program (IRCCP) with a matched group of students as controls. All identified similar results, showing strong evidence for the impact of diversity on learning outcomes. Students who had experienced the most diversity in classroom settings and in informal interactions with peers showed the greatest engagement in active thinking processes, growth in intellectual engagement and motivation, and growth in intellectual and academic skills.

Results also strongly support the value of experiencing diversity in the classroom and informal interactions on engagement of various kinds of citizenship activities and engagement with people of other races or ethnicities, referred to as "democracy outcomes." Students who had experienced more diversity were more likely to acknowledge that group differences are compatible with the interests of the broader community.

The broader community is also favorably impacted, results show, by attending a college with substantial diversity. Being white was positively associated with reports of diversity among friends, neighbors, and coworkers later in life. Informal interactions in diverse groups, for example, participating in racial/cultural awareness workshops, discussing racial and ethnic issues and socializing interracially, and having diverse close friends in college, were especially influential in accounting for later patterns of social and work life integration. Enrollment in an ethnic studies course in college was related to a number of social and intellectual outcomes after college, such as diversity among friends and neighbors five years after college; strong academic motivation and growth in learning; high value placed on intellectual and academic skills; and personal belief in being prepared for graduate school. 
Overall, the results of the post-college study show that the positive impact of racial and ethnic diversity experienced in college has lasting rather than ephemeral influence. As Gurin observed, the analyses confirm that the "long-term pattern of racial separation noted by many social scientists can be broken by diversity experiences in higher education" (p. 101). ${ }^{8}$

One finding of note to me, as a behavioral scientist, is that positive changes in areas related to cultural awareness - for example, "promoting racial understanding" and "influencing social values"were associated with undergraduate academic concentrations in the social sciences and humanities more so than in the basic sciences, engineering, nursing, or business. All of these outcomes are more prevalent on campuses that have a higher degree of institutional commitment to diversity when faculty teaching and research reflect, to some degree, diversity and multiculturalism and there are student diversity experiences, such as access and exposure to courses in race and ethnicity.

As part of the University of Michigan's defense, data from legal education at Michigan were also presented. In his expert testimony on behalf of the University of Michigan, Syverud ${ }^{21}$ explained how racial and ethnic heterogeneity in the classroom produces an examination of assumptions and frank discussion about the law that cannot be achieved in environments without such diversity. One example he provides is from his teaching in civil procedure, in which students engage in role play for jury selection procedures. Syverud describes students as shocked and enlightened when unexpected differences in assumptions about human nature, experience, and the law are analyzed in relation to jury composition.

Other studies of law graduates at Michigan ${ }^{22}$ show that while all graduates over a twenty-sevenyear period provide significant community service and pro bono work, minority graduates tend to average twice the number of hours than do their white counterparts. With a critical mass of students, can you imagine the educational benefits of diversity if we in academic dentistry organized more of our curriculum around health disparities?

Educational benefits are also improved by no longer focusing on deficiency and disadvantage, but from an orientation of strength. ${ }^{23}$ Admissions experts know that no student can possibly be evenly prepared on all dimensions for what he or she will face in a health professions school. Students come to us with a range of experiences and preparations, and they succeed, just beautifully. I have replaced the words "disadvantaged student" in my vocabulary with the words "unevenly prepared student." When we think this way and when we fundamentally understand the benefits of diversity, our awareness necessarily moves away from a focus on remediation and disadvantage. Focusing more on cultural pluralism and cultural identity as we assemble our classes, we build in elements that contribute to positive additional outcomes for the classroom and curriculum.

\section{Diversity, Social Capital, and Trust: The Differently Prepared Student}

So, when will we have the courage to ask the question anew about admissions? Are we simply going to continue to recruit students prepared for the most part in the traditional pattern and sequence? Or are we ready to look at skills and experiences that present students who will succeed, but who might be differently prepared? Students selected for admission to dental school from undergraduate institutions with high degrees of student and faculty diversity, classroom diversity, and social interaction diversity will be those students who provide enriched and appropriately complex approaches to patient care. I predict that it is these students who will extend the reach of our schools into the community for preventive programs, health care, and youth services. They too, most likely, will be the best recruiters for future classes.

But do we in health professions education attenuate or even squander the investment made at the undergraduate level? There are nontraditionally prepared students who are interested in topics related to social inequality, health disparities, history, economics, and cultural studies, as well as students who are more traditional in their preparation - both coming to us interested and motivated to continue their professional education and service in diverse communities. For both types of students, academic dentistry is at best unevenly prepared, and at worst underprepared, for the education students are expecting.

At Michigan, Dr. Terrence Joiner, ${ }^{24}$ a pediatrician educator, teaches undergraduates in a course entitled "Health Care, Privilege, and Community." The course is part of a service learning curriculum in the Michigan Community Scholars Program, an 
undergraduate learning community. Dr. Joiner describes his course as providing "undergraduates an opportunity to understand the evolution of American health care in a multicultural context." Further, he says, "the course examines how medical care has been delivered to different ethnic communities in the United States focusing on issues of racism, patient rights, civil rights, and health disparities." He places some emphasis on the historical changes in health professions over the last century and uses this to provide a context for understanding health disparities in the present. In Dr. Joiner's essay about the experience, he says that, "as a teacher, biomedical researcher, and clinical practitioner, diversity has enriched [his] career" and teaching in the community learning program is important to him to "watch diversity work."

Michigan is not the only school with learning communities and service learning programs. There are many students in these programs nationally, each with its own emphasis, but all with the basic orientation for promoting engagement and community connection and contributing to a diverse democracy. (These outcomes are the building blocks of social cohesion, viz., social capital.) Are we systematically testing this pathway for students who perhaps for the first time are thinking about a career in health professions? And are we interested in flexible approaches for preparing them for the admission process? For students who have been engaged in these programs, are we continuing their education and contributing to their commitment and values? Or are we squandering an opportunity to address the full range of issues that could be represented in a responsible curriculum, a curriculum that exemplifies a distinct integrity aligned with addressing oral health and health care in a highly diverse society, including the complexities of health disparities? We need to ask ourselves how to capitalize on the forces, the elements, the urgency for broader experiences that are all part of the educational benefits of diversity for students, health professionals, and society. Will academic dentistry be able to keep up? Although potentially uncomfortable, these are the questions that we must continue to examine at our schools and with ADEA if we are to remain vital and relevant to higher education and to the public good.

A second-year dental student at Michigan, Carlos Smith, is working with Dr. Marita Inglehart, a behavioral scientist, and Dr. Todd Ester, clinician educator and director of multicultural affairs, on a project to examine how background factors in the lives of dental students and graduates in practice influence their professional lives and their interest and action for treating underserved patients. With responses from over 325 dental students and 234 responses from graduates over a twenty-year period, the data are very instructive. ${ }^{25}$ Students and alumni who reported having high degrees of contact with diverse groups early in life through high school reported that they were more likely to treat patients from diverse groups (alumni) or intended to treat diverse patient groups (students). Alumni and students who believed their dental education prepared them well to treat patients in different communities were likely to express satisfaction with the dental profession because it allowed them to make a difference in the lives of others and interact with patients from a variety of backgrounds, including treating or intending to treat people with disabilities. The researchers also reported that African American alumni, when compared with white alumni, treated significantly more African American patients and that African American dental students, when compared with white students, had stronger beliefs/expectations that they will treat diverse patients in their future practice of dentistry. The authors suggest that curriculum and curricular arrangements and experience with diversity prior to dental school are related to professional behaviors and choices or intentions for future choices about practice that would aid the underserved and unserved.

There is clearly a very full range of educational benefits from diversity, both for the individual and for society. I have also drawn attention to opportunities to increase the numbers of students in the pipeline who are minorities, as well as students in general, who are interested in health disparities and social justice. All will enhance and increase the educational benefits from a diverse dental education and suggest that we are building capacity for social capital from diversity. While much has been written on social capital, ${ }^{4,5,20}$ suffice it to say that social capital is defined as "the stock of active connections among people; the trust, mutual understanding, and shared values and behaviors that bind the members of ... communities and make cooperative action possible." ${ }^{26}$ A fair amount of work is emerging, too, ${ }^{4,5,20}$ that connects social capital to the health of communities and, somewhat obviously, to just those characteristics that can be used to describe successful partnerships between communities and dental schools. With each student we graduate, from programs that have maximized diversity experiences, 
in the classroom, in social interactions, in the composition of our classes, in school-based clinics or community clinics, we enhance and extend the democracy outcomes discussed earlier and increase the potential of sustaining broader response to the full range of health needs in society. Through diversity, we build capacity for social capital.

\section{Diversity and Admissions Practices: Practical Implications of Supreme Court Decisions}

In the Michigan Law School case Grutter v. Bollinger et al., the U.S. Supreme Court held that diversity is a compelling interest in higher education and that race is one of a number of factors that can be taken into account to achieve the educational benefits of a diverse student body. The law school's individualized review process was ruled to be narrowly tailored to achieve the educational benefits of diversity. Importantly, the goal of attaining a critical mass of underrepresented minority students in the law school was found not to transform its admissions practices into a quota system. In Gratz et al. v. Bollinger et al., the court held that race is one of a number of factors that can be considered in undergraduate admissions, just like the law school case. However, the automatic distribution of points to students from underrepresented minority groups did not conform to the narrowly tailored standard.

With respect to narrow tailoring, we know from the court that race can be one of many "plus" factors and that reviews for admission need to be individualized and "holistic" with consideration for all pertinent elements of diversity. Quotas or separate processes for admission are prohibited, but seeking a "critical mass" is permitted. Further, in consideration of race, no mechanical or automatic weights can be used in decision making, nor can race be a predominant factor. There was guidance for consideration of race-neutral alternatives, but also the recognition that institutions do not need to choose between excellence and diversity. Finally, programs are expected to be time limited, with consideration for sunset provisions and periodic review. The court signaled an expectation, with a received message somewhere between aspiration and mandate, that affirmative action programs will not be needed in twenty-five years. ${ }^{27}$
Full explanations of the Michigan cases, the defendants' and plaintiffs' briefs, expert testimonies, and amicus briefs can be found on the university's website, ${ }^{3}$ along with guidance for admissions, financial aid, and outreach programs. A number of significant amicus briefs were filed on behalf of the University of Michigan in support of its defense. These briefs represented more than eighty organizations and included higher education associations and academic societies, Fortune 500 corporations, and governmental and industry-related entities. All strongly supported the university's use of race in admissions. Citing case law, classic writings on democracy, empirical data from higher education, and business venue demographics, the briefs outlined in clear terms the necessity of diversity for a more complete education and for experiences that will foster a talented, successful workforce in an increasingly global marketplace. One of the most noteworthy briefs of all came from the military. Retired leaders and others presented a compelling case on the importance of diversity to the nation's security and an effective military. (These briefs are available through the University of Michigan, Office of the Vice President and General Counsel, or at www.umich.edu/ urel/admissions/gra_amicus/.)

One of the very best summaries of the cases along with clear, how-to guidance can be found in a document prepared by the American Association of Medical Colleges (AAMC) ${ }^{28}$ Toward the end of this document, there is a summary list for formulating admissions practices and polices that include race and ethnicity-conscious information and are narrowly tailored and in keeping with the rulings of the court. The list has clear and obvious practice implications and can be used to guide each institution's individual, contextually relevant practice.

Nine basic considerations are provided on the AAMC checklist. They are:

- Address, preferably in writing, the various reasons why having a racially and ethnically diverse student body is educationally valuable; this can be done in an admissions mission statement (Office of Admissions), with parallel statements in our mission statements or similar type documents;

- Ensure that there are no quotas or set-asides and that, regardless of race or ethnicity, applicants are considered in the same competitive pool using the same policies, procedures, and admissions committee members;

- Ensure that applicants receive individualized, holistic consideration using a flexible policy in which 
race/ethnicity is one of a number of factors taken into account;

- Adopt a definition of diversity that includes but is not limited to racial and ethnic diversity;

- Make a good-faith consideration of workable raceneutral alternatives to race-conscious policies, mindful that all race-neutral alternatives need not be exhausted before narrowly tailored, race-conscious admission policies are implemented (percent plans don't work for graduate and professional schools; percent plans constrain other diversity that comes from whole-file review);

- Consider incorporating into the admissions policy a periodic review process or a sunset provision as a means for reevaluating whether race and ethnicity remain necessary as factors in admissions decision in the future;

- Support research and analyze data that confirm the benefits of diversity;

- Consider hiring additional admissions officers to ensure that the necessary individualized review of each applicant takes place; and

- Review whether workable race-neutral programs exist for attracting a critical mass of students from underrepresented racial and ethnic groups.

The University of Michigan has placed in writing the reasons why having a racially and ethnically diverse class is educationally valuable. We have a highly visible mission statement ${ }^{29}$ for the undergraduate Office of Admissions:

The University of Michigan seeks to enroll and graduate applicants who will develop and grow educationally and personally and will contribute to the university community, the State of Michigan, and the broader society. To that end, the role of the Undergraduate Admissions Office is to recruit, admit, and encourage enrollment of applicants who are academically excellent, accomplished in extracurricular endeavors, and broadly diverse. It is the university's experience and judgment that this mix of students will foster the vibrant educational atmosphere that provides the best educational experience for all students.

Note the notion of "broadly diverse" in the mission statement. We have operationalized this to mean race, ethnicity, socioeconomic status, urban/ rural, other geographic locations, first generation college, disability status, and so on. There is also an overview statement accompanying the mission state- ment, which emphasizes our commitment to individualized, holistic consideration for each applicant.

\section{Outreach, Recruitment, and Retention}

Principles that apply to admissions may also apply to outreach and mentoring programs or related pipeline programs for recruitment and retention of students. During the Michigan lawsuits, the Center for Individual Rights (CIR) declared such programs as subject to the same or similar legal challenges as admissions. Other agencies like the Center for Equal Opportunity and American Civil Rights Institute wrote letters during the course of the lawsuits to numbers of colleges and universities, indicating that they will challenge such programs, particularly if they are restricted by race or ethnicity. ${ }^{27}$ Some institutions responded prematurely and conservatively and now must be encouraged to return to practices that were in place, if consistent with the court's rulings. If your school suspended or ended an outreach program or special program related to recruitment and retention, I'd urge you to reassess the decision and analyze what might work now, since the court's rulings.

According to legal analysis and expert advice, we are guided by what the court stated in the Grutter decision, that "context" is important, meaning that "each program must be evaluated carefully on a caseby-case basis in terms of its history, purposes and impact on minority and majority students (among other factors)" (p. 13). ${ }^{27}$ As we review programs, we consider the following and offer them as guides for others, all with an approach that addresses building the pipeline so that students will be prepared ahead for the competitive admissions process in order to preserve a diverse class that experientially provides benefit to all students.

The questions below are taken directly from analyses prepared through the Office of the General Counsel at Michigan ${ }^{27}$ and are important to consider, in general, in the design of programs:

- What are the history and purpose of the program, including any external relationships involved (e.g., participation in a consortium with other institutions)?

- How does the program relate to other university programs (e.g., admissions, financial aid, etc.)?

- Does the program directly support the university's admissions and recruitment efforts, i.e., is it de- 
signed to increase applications, the yield of students with particular types of backgrounds and interests, etc.?

- What criteria are considered for participation in the program? Are some nonminority students eligible to participate (e.g., based on socioeconomic disadvantage or other factors)? (Included here could be students' interest in addressing health disparities or participating in community-based clinical education.)

- What benefits are related to participation in the program? To what extent do other students have access to the same types of resources or services offered in the program?

- Have alternatives been considered in which race plays less of a role (including race-neutral alternatives)? To what extent would such alternatives impact the purpose and success of the program?

\section{It's All About the Pipeline}

We now have a body of exquisitely clear, welldocumented sources that provide evidence and argument for the range of actions we must take to address the educational and experiential pipeline. These documents - the surgeon general's report on oral heath, ${ }^{30}$ the Institute of Medicine (IOM) report "Unequal Treatment: Confronting Racial and Ethnic Health Disparities in Healthcare," ${ }^{31}$ the IOM report "In the Nation's Compelling Interest: Ensuring Diversity in the Health Care Workforce, ${ }^{, 32}$ and most recently the stunning Sullivan Commission report, "Missing Persons: Minorities in the Health Professions" ${ }^{33}$ - have all been produced within the last three or four years. They are up-to-date, urgent, and necessary. Each document provides material that relates to nearly every aspect of the work ahead, from rewriting mission statements to designing outreach and admissions programs, to curriculum and clinical education for addressing health disparities, to faculty development and institutional climate assessment and improvement. There are lessons to learn about white privilege and the development of racial and ethnic identity and what influences how pathways are found, as Beverly Tatum tells us in her book Why Are All the Black Kids Sitting Together in the Cafeteria?, ${ }^{34}$ as well as lessons about how long- and short-term choices are made with and without resources, as poignantly and eloquently told in the stories of Ben Carson (Gifted Hands) ${ }^{35}$ and Cedric Jennings ( $A$ Hope in the Unseen). ${ }^{36}$
Unless we boldly and actively build and fill the pipeline, we will experience the unintended consequences of competition for groups of students, in numbers that will not begin to meet the critical mass needed across dental education to realize the educational benefits of diversity or the growing health care needs of an increasingly diverse nation or to address health disparities. In the twenty-five-year timeline given by Justice O'Connor, whether as aspiration, motivation, or deadline, we must act with constancy and purpose to achieve these important goals.

First, we must realize that work on any part of the pipeline will make a difference: outreach programs for grades six through twelve that include math and science tutoring, curriculum guidance, parent programs; college-level outreach from community colleges to regional four-year schools to researchintensive universities; more focused outreach for admissions portfolio preparation and application completion; summer science programs for nontraditional students and programs on health disparities; faculty development and climate assessment; and, of course, curriculum change to include health disparities and clinical education in community-based settings with pedagogical support for "sense-making" throughout the experience.

Second, we must think about economies of scale and then design and test regional programs to build the pipeline. There are a number of very creative approaches that are emerging, like the New York State postbaccalaureate program to prepare students for second application to medical school; or regional summer pipeline programs that serve four or five schools by taking fifty or sixty students without duplication of effort; or the design of programs like the Posse Foundation-University Partnership ${ }^{37}$ that help clear the barrier-strewn pathway from high school to undergraduate education for students in urban areas, segregated high schools, and segregated communities. The Posse Foundation supports programs that work with groups of students nominated from their schools for qualities linked to success other than straight academic accomplishment, like leadership qualities and persistence. The program helps the students prepare for the college admission process and connects them to selective schools that would admit a small group of students from the same metropolitan area as a "tightly bonded group or posse." During their first year of college and beyond, the Posse connection continues and provides support, counseling, and other resources that might otherwise be difficult to find. 
Third, I urge that dental schools use aggressively the literature that has been developed since the Supreme Court decisions and seek second opinions if your campus general counsels are constrained in their interpretations of the Supreme Court decisions. Vice President and General Counsel Marvin Krislov at Michigan and Vice President and General Counsel Jonathan Alger at Rutgers are excellent resources, as is the University of Michigan website. These individuals provide expert guidance and have prepared information for institutions that may have questions lingering or delays in program progress. It's also important to consult the AAMC document, Assessing Medical School Admissions Policies, ${ }^{28}$ and parallel documents from the American Association for the Advancement of Science (AAAS) and National Action Council for Minorities in Engineering (NACME) ${ }^{38}$ or the College Board document, Diversity in Higher Education: A Strategic Planning and Policy Manual Regarding Federal Law in Admissions, Financial Aid, and Outreach ${ }^{39}$ All three of these documents are available online; the information is relevant, practical, and immediately applicable.

Last, let's congratulate and celebrate the progress that ADEA's leadership has made in the areas of diversity and equity. Our fortune is beyond words to have the guidance, wisdom, and constancy of Dr. Jeanne Sinkford, Associate Executive Director and Director of the Center for Equity and Diversity. I would also say that we must have constancy and persistence as members of ADEA, an organization that holds my deepest affections, and push the volunteer Board of Directors to keep the work of diversity in front of them and in front of us. We must be unstinting with effort and with resources.

We cannot afford to fail, and I know we won't.

\section{Acknowledgments}

The author thanks Dr. Patricia O'Connor and Dr. Allan Formicola for their comments and suggestions on this article and previous drafts of related work.

\section{REFERENCES}

1. University of Michigan, October, 14, 1997. At: www.umich.edu/ newsinfo/index.html?Releases/1997/ Oct97/chr101497d. Accessed: July 2005.

2. University of Michigan, June 23, 2003. At: www.umich. edu/news/Releases/2003/Jun03/comments.html. Accessed: July 2005.
3. University of Michigan, 2003, 2004. At: www.umich.edu/ $\sim$ urel/admissions/overview/challenge.html. Accessed: July 2005.

4. Saegert S, Thompson JP, Warren MR, eds. Building and using social capital in poor communities. New York: Sage Publications, 2001.

5. James SA, Schulz AJ, van Olphen J. Social capital, poverty, and community health: an exploration of linkages. In: Saegert S, Thompson P, Warren M, eds. Building and using social capital in poor communities. New York: Sage Publications, 2001:165-88.

6. Bowen WG, Bok D. The shape of the river: long-term consequences of considering race in college and university admissions. Princeton: Princeton University Press, 1998.

7. Gurin P, Lehman JS, Lewis E. Defending diversity: affirmative action at the University of Michigan. Ann Arbor: University of Michigan Press, 2004.

8. Gurin P. Expert report of Patricia Gurin, Grat et al. v. Bollinger et al., No. 97-75321 (E.D. Mich.; Grutter et al. v. Bollinger et al., No. 97-75928). In: The compelling need for diversity in higher education, 99-234. Ann Arbor: University of Michigan, Office of the Vice President and General Counsel, 1999.

9. Gurin P. Evidence for the educational benefits of diversity in higher education: response to the critique by the National Association of Scholars of the expert witness report of Patricia Gurin. Gratz et al. v. Bollinger et al., No. $97-75321$ (E.D. Mich.; Grutter et al. v. Bollinger et al., No. 97-75928). Ann Arbor: University of Michigan, Office of the Vice President and General Counsel, 2001. At: www.umich.edu/!urel/admissions/new/gurin.html.

10. Gurin P. Evidence for the educational benefits of diversity in higher education: an addendum, Gratz et al. v. Bollinger et al., No. $97-75321$ (E.D. Mich.; Grutter et al. v. Bollinger et al., No. 97-75928. Ann Arbor: University of Michigan, Office of the Vice President and General Counsel, 2001. At: www.umich.edu/ urel/admissions/ new/gurin_add.html.

11. Gurin P, Dey EL, Hurtado S, Gurin G. Diversity and higher education: theory and impact on educational outcomes. Harvard Educational Review 2002;72(3):330-66.

12. Gurin P, Nagda BA, Lopez GE. The benefits of diversity in education for democratic citizenship. J Social Issues 2004;60(1):17-34.

13. Light R. Making the most of college: students speak their minds. Cambridge: Harvard University Press, 2001.

14. Sax LJ, Astin AW. Developing "civic virtue" among college students. In: Gardner JN, VanderVeer G, et al., eds. The senior year experience: facilitating integration, reflecting closure, and transition. San Francisco: JosseyBass, 1998:133-51.

15. Astin AW. What matters in college? four critical years revisited. San Francisco: Jossey-Bass, Inc., 1993.

16. Astin AW. Diversity and multiculturalism on the campus: how are students affected? Change 1993;March/April: 44-9.

17. Orfield G. Introduction. In: Orfield G, Kurlaender M, eds. Diversity challenged: evidence on the impact of affirmative action. Cambridge: Harvard Education Publishing Group, 2001:1-30. 
18. Orfield G, Kurlaender M, eds. Diversity challenged: evidence on the impact of affirmative action. Cambridge: Harvard Education Publishing Group, 2001.

19. Orfield G, Whitla D. Diversity in legal education: student experiences in leading law schools. In: Orfield G, Kurlaender M, eds. Diversity challenged: evidence on the impact of affirmative action. Cambridge: Harvard Education Publishing Group, 2001:143-74.

20. Tedesco LA. The role of diversity in the training of health professionals. In: Smedley BD, Stith AY, Colburn L, Evans $\mathrm{CH}$, eds. The right thing to do, the smart thing to do: enhancing diversity in the health professions. Washington, DC: Institute of Medicine, National Academies Press, 2001:36-56.

21. Syverud KD. Expert report of Kent D. Syverud, Grutter et al. v. Bollinger et al., No. 97-75928 (E.D. Mich.). In: The compelling need for diversity in higher education. Ann Arbor: University of Michigan, Office of the Vice President and General Counsel, 1999:265-7.

22. Chambers DL, Lempert RO, Adams TK. Doing well and doing good: the careers of minority and white graduates of the University of Michigan Law School, 1970-1996. Law Quadrangle Notes. Ann Arbor: University of Michigan Law School, Summer 1999.

23. Trickett EJ, Watts RJ, Birman D. Toward an overarching framework for diversity. In: Trickett EJ, Watts RJ, Birman D, eds. Human diversity: perspectives on people in context. San Francisco: Jossey-Bass, Inc., 1994:7-26.

24. Joiner TA. Promoting diverse democracy in health care. In: Galura JA, Pasque PA, Schoem D, Howard J, eds. Engaging the whole of service-learning, diversity, and learning communities. Ann Arbor: The OCSL Press at the University of Michigan, Edward Ginsberg Center for Community Service Learning, 2004:113-20.

25. Smith C, Ester TV, Inglehart MR. Providing care for underserved patients: the role of dental education. Abstract no. 12. J Dent Educ 2005;69(1):112-3.

26. Cohen D, Prusak L. In good company: how social capital makes organizations work. Boston: Harvard Business School Press, 2001.

27. Alger J. University of Michigan, October 11, 2003. At: www.umich.edu/ urel/admissions/overview/ challenge.html. Accessed: July 2005.
28. American Association of Medical Colleges. Assessing medical school admissions policies: implications of the U.S. Supreme Court's affirmative action decisions, 2004. At: www.aamc.org. Accessed: July 2005.

29. University of Michigan. Application, guidelines and process, undergraduate admissions, mission statement, 20042005. At: www.admissions.umich.edu/process/review/ intro/. Accessed: July 2005.

30. Oral health in America: a report of the surgeon general. Rockville, MD: U.S. Department of Health and Human Services, National Institute of Dental and Craniofacial Research, National Institutes of Health, 2000.

31. Smedley BD, Butler AS, Nelson AR, eds. Unequal treatment: confronting racial and ethnic disparities in health care. Washington, DC: Institute of Medicine, National Academies Press, 2003.

32. Smedley BD, Butler AS, Bristow LR, eds. In the nation's compelling interest: ensuring diversity in the health care workforce. Washington, DC: Institute of Medicine, National Academies Press, 2004.

33. The Sullivan Commission. Missing persons: minorities in the health professions. A report on the Sullivan Commission on Diversity in the Healthcare Workforce, 2004. At: www.sulllivancommission.org. Accessed: July 2005.

34. Tatum BD. Why are all the black kids sitting together in the cafeteria? New York: Basic Books, 1997.

35. Carson B with Murphey C. Gifted hands: the Ben Carson story. Grand Rapids, MI: Zondervan Press, 1990.

36. Suskind R. A hope in the unseen. New York: Broadway Books, 1998

37. Posse Foundation. At: www.possefoundation.org/main/ university/index.cfm. Accessed: July 2005.

38. Malcolm SM, Chubin DE, Jesse JK. Standing our ground: a guidebook for STEM educators in the post-Michigan era, 2004. At: www.aaas.org/standingourground/. Accessed: July 2005.

39. Coleman AL, Palmer SR, Nixon Peabody LLP. Diversity in higher education: a strategic planning and policy manual regarding federal law in admissions, financial aid, and outreach. 2nd ed. Washington, DC: College Entrance Examination Board, 2004. 